\title{
BMJ Open Mortality, greenhouse gas emissions and consumer cost impacts of combined diet and physical activity scenarios: a health impact assessment study
}

\author{
Marko Tainio, ${ }^{1,2}$ Pablo Monsivais, ${ }^{1}$ Nicholas RV Jones, ${ }^{1}$ Christian Brand, ${ }^{3}$ \\ James Woodcock ${ }^{1}$
}

To cite: Tainio $\mathrm{M}$, Monsivais $P$, Jones NRV, et al. Mortality, greenhouse gas emissions and consumer cost impacts of combined diet and physical activity scenarios: a health impact assessment study. BMJ Open 2017;7:e014199.

doi:10.1136/bmjopen-2016014199

- Prepublication history and additional material is available. To view please visit the journal (http://dx.doi.org/ 10.1136/bmjopen-2016014199).

Received 7 September 2016 Revised 26 October 2016 Accepted 8 December 2016

\section{CrossMark}

${ }^{1}$ MRC Epidemiology Unit, Centre for Diet and Activity Research, University of Cambridge School of Clinical Medicine, Institute of Metabolic Science, Cambridge, UK

${ }^{2}$ Systems Research Institute, Polish Academy of Sciences, Warsaw, Poland

${ }^{3}$ Transport Studies Unit,

School of Geography and the Environment, University of Oxford, Oxford, UK

Correspondence to Dr Marko Tainio; mkt27@medschl.cam.ac.uk

\section{ABSTRACT}

Objective: To quantify changes in mortality, greenhouse gas (GHG) emissions and consumer costs for physical activity and diet scenarios.

Design: For the physical activity scenarios, all car trips from $<1$ to $<8$ miles long were progressively replaced with cycling. For the diet scenarios, the study population was assumed to increase fruit and vegetable (F\&V) consumption by $1-5$ portions of $F \& V$ per day, or to eat at least 5 portions per day. Health effects were modelled with the comparative risk assessment method. Consumer costs were based on fuel cost savings and average costs of $F \& V$, and $G H G$ emissions to fuel usage and F\&V production.

Setting: Working age population for England.

Participants: Data from the Health Survey for England, National Travel Survey and National Diet and Nutrition Survey.

Primary outcomes measured: Changes in premature deaths, consumer costs and GHG emissions stratified by age, gender and socioeconomic status (SES).

Results: Premature deaths were reduced by between 75 and 7648 cases per year for the physical activity scenarios, and 3255 and 6187 cases per year for the diet scenarios. Mortality reductions were greater among people of medium and high SES in the physical activity scenarios, whereas people with lower SES benefited more in the diet scenarios. Similarly, transport fuel costs fell more for people of high SES, whereas diet costs increased most for the lowest SES group. Net GHG emissions decreased by between 0.2 and 10.6 million tons of carbon dioxide equivalent $\left(\mathrm{MtCO}_{2} \mathrm{e}\right)$ per year for the physical activity scenarios and increased by between 1.3 and $6.3 \mathrm{MtCO}_{2} \mathrm{e} /$ year for the diet scenarios.

Conclusions: Increasing F\&V consumption offers the potential for large health benefits and reduces health inequalities. Replacing short car trips with cycling offers the potential for net benefits for health, GHG emissions and consumer costs.

\section{INTRODUCTION}

Physical inactivity and low-quality diets are important risk factors for poor health at the

\section{Strengths and limitations of this study}

- We quantified the impact of five physical activity and six diet scenarios on all-cause mortality, greenhouse gas (GHG) emissions and consumer costs for the adult population of England, and stratified mortality and cost impacts by age, sex and socioeconomic status (SES).

- To the best of our knowledge, this is the first study that estimated health, consumer cost and GHG impacts of physical activity and diet scenarios, and estimated SES differences in the health and cost outcomes.

- The study was based on 'what if' hypothetical changes in physical activity and diet without consideration of how this change could be achieved in the study population.

global level. When expressing the health effects as disability-adjusted life-years, the Global Burden of Disease (GBD) 2013 study gave dietary risks as the most important and low physical activity as the 14th most important risk factors at the global level. ${ }^{1}$ Based on a specific analysis of the GBD 2013 data for England, dietary risks were the top risk factor, with low physical activity the ninth most significant factor. ${ }^{2}$ This indicates that changes in physical activity and diet can potentially have large impacts on public health. In this study, we investigated two potential changes that have been known to influence the above outcomes: (1) replacing short car trips with cycling $^{3-6}$ and (2) increasing fruit and vegetable $(\mathrm{F} \& \mathrm{~V})$ consumption. $^{78}$

The benefits of such changes will vary in a population by age, gender and socioeconomic status (SES). The GBD 2013 analysis for England used a deprivation index varying from 1 (least deprived) to 5 (most deprived) and, in general, people in the most deprived group were more ill and had 
lower life expectancy than the average population. ${ }^{2}$ This suggests that the more deprived people may benefit more from increased physical activity and diet-related interventions than the less deprived. ${ }^{9}$ This raises questions on how to design interventions that target people on low SES, ${ }^{10}{ }^{11}$ and how the increase of cycling and $\mathrm{F} \& \mathrm{~V}$ consumption would impact different SES groups.

Changes in cycling activity and F\&V consumption may have other consequences, such as changes in individual's expenditure and greenhouse gas (GHG) emissions. If people substituted motorised transport with active transport (walking or cycling), the expenditure on transport and carbon emissions might decrease. The Living Costs and Food Survey for 2011 estimated that 14\% of the household expenditure costs were due to transport, of which $55 \%$ were due to operational costs such as fuel expenditure. ${ }^{12}$ Similarly, GHG emissions from motorised travel may also decrease. In the UK, about $21 \%$ of domestic GHG emissions are from transport, with passenger cars accounting for $58.3 \%$ of total transport emissions. ${ }^{13}$ For passenger cars alone, trips under 5 miles account for $\sim 21 \%$ of GHG emissions, ${ }^{13}$ indicating that replacing short car trips with active transport may have significant GHG emission impacts.

In contrast, increased consumption of $\mathrm{F} \& \mathrm{~V}$ could increase costs and GHG emissions. In the UK, 9.5\% of domestic GHG emissions were from agriculture. ${ }^{14}$ The 2011 Living Costs and Food Survey estimated that 11\% of total household expenditure was for food and nonalcoholic drinks, with $15 \%$ of this for $\mathrm{F} \& \mathrm{~V} .{ }^{12}$ Analysis of nationally representative data from the UK has shown that diets which meet the recommended intake of five portions of $\mathrm{F} \& \mathrm{~V}$ per day are typically more expensive, and that $\mathrm{F} \& \mathrm{~V}$ are more expensive than other food groups. ${ }^{15} 16$ Similarly, data from the 2011 Living Costs and Food Survey showed that household expenditure for food and non-alcoholic drinks varied from $8 \%$ to $20 \%$ for the highest and lowest SES groups, ${ }^{12}$ respectively, indicating that changes in food costs may impact lower SES households more than others.

This study aimed to quantify the health, consumer cost and GHG emission changes for five physical activity and six diet scenarios for the adult population in England. The health benefits and changes in consumer costs were estimated by age, gender and SES of the study population, with further assessment of the changes in national GHG emissions. The main purpose was to quantify and compare how different SES groups would be affected under each scenario. To the best of our knowledge, this is the first study that examined the health, GHG emission and consumer cost impacts of physical activity and diet scenarios.

\section{METHODS}

\section{Overview and study population}

We combined background travel, physical activity and F\&V consumption data to generate a synthetic baseline population for England (figure 1). Health effects of physical activity and F\&V consumption were modelled by combining changes in exposure with background allcause mortality and dose-response functions (DRFs).

All calculations were performed on the working age population (20-69 years old) of England, totalling 34.2 million adults. The population was divided into five age groups $(20-29,30-39,40-49,50-59,60-69)$, gender (male, female) and four SES groups (table 1). ${ }^{17}$ SES was
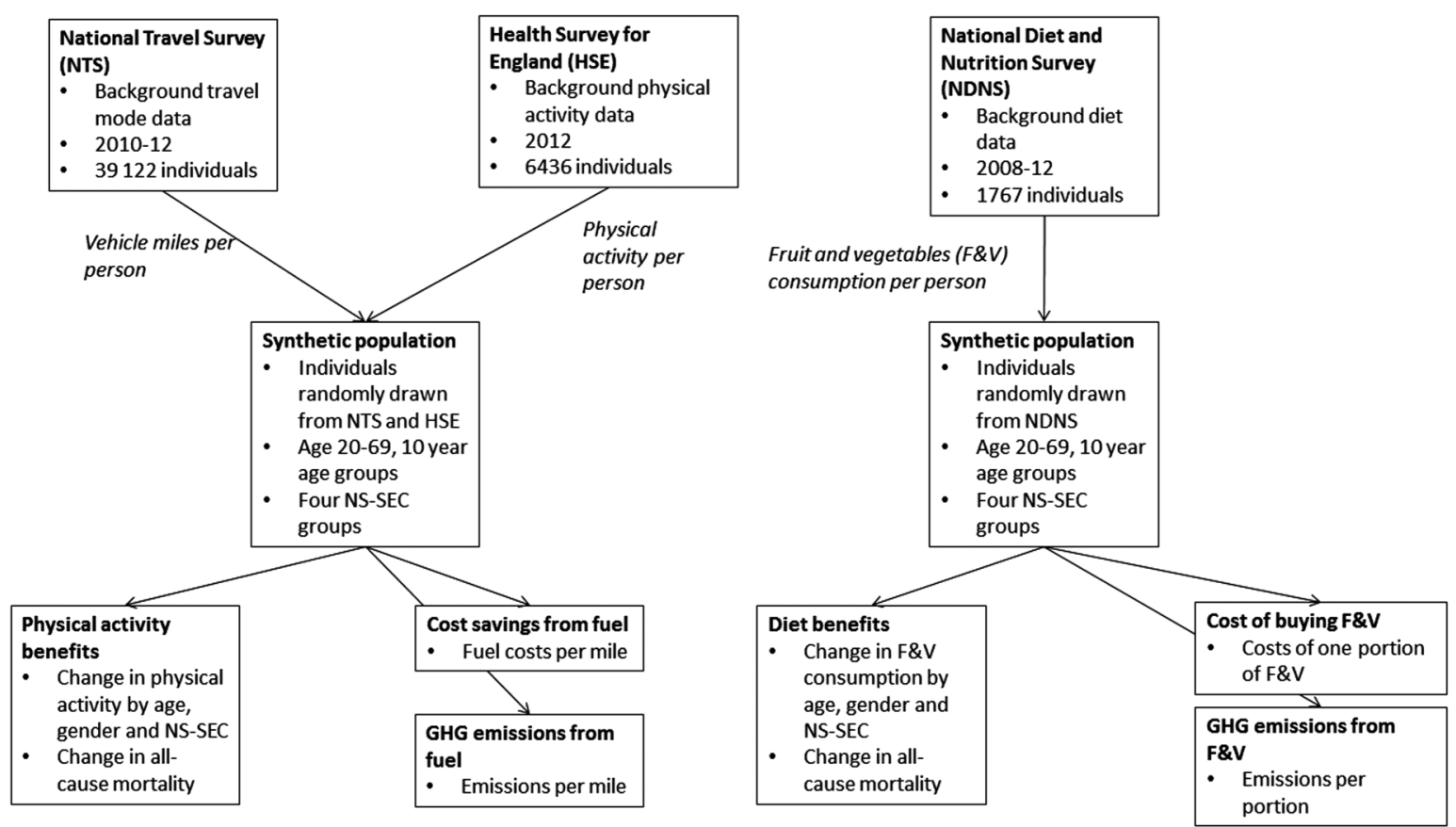

Figure 1 General overview of the calculation. NS-SEC, National Statistics Socio-Economic Classification. 
Table 1 Percentage of population by age, gender and NS-SEC (total number of people 34.15 million)

\begin{tabular}{|c|c|c|c|c|c|c|}
\hline & 20-29 & $30-39$ & 40-49 & $50-59$ & 60-69 & Sum \\
\hline \multicolumn{7}{|l|}{ Female, NS-SEC } \\
\hline Higher managerial, administrative and professional occupations & $2.7 \%$ & $4.2 \%$ & $4.1 \%$ & $3.1 \%$ & $2.2 \%$ & $16.3 \%$ \\
\hline Intermediate occupations & $2.1 \%$ & $2.5 \%$ & $3.2 \%$ & $2.7 \%$ & $2.5 \%$ & $12.9 \%$ \\
\hline Routine and manual occupations & $3.1 \%$ & $2.6 \%$ & $3.3 \%$ & $3.2 \%$ & $3.4 \%$ & $15.6 \%$ \\
\hline Never worked and long-term unemployed & $2.7 \%$ & $1.1 \%$ & $0.9 \%$ & $0.5 \%$ & $0.4 \%$ & $5.6 \%$ \\
\hline Sum & $10.6 \%$ & $10.4 \%$ & $11.5 \%$ & $9.5 \%$ & $8.5 \%$ & $50.4 \%$ \\
\hline \multicolumn{7}{|l|}{ Male, NS-SEC } \\
\hline Higher managerial, administrative and professional occupations & $2.6 \%$ & $4.3 \%$ & $4.4 \%$ & $3.4 \%$ & $2.8 \%$ & $17.6 \%$ \\
\hline Intermediate occupations & $1.7 \%$ & $2.1 \%$ & $2.6 \%$ & $2.2 \%$ & $2.0 \%$ & $10.6 \%$ \\
\hline Routine and manual occupations & $3.7 \%$ & $3.2 \%$ & $3.6 \%$ & $3.3 \%$ & $3.2 \%$ & $16.9 \%$ \\
\hline Never worked and long-term unemployed & $2.5 \%$ & $0.7 \%$ & $0.6 \%$ & $0.4 \%$ & $0.2 \%$ & $4.5 \%$ \\
\hline Sum & $10.6 \%$ & $10.3 \%$ & $11.3 \%$ & $9.3 \%$ & $8.1 \%$ & $49.6 \%$ \\
\hline
\end{tabular}

measured by using the National Statistics SocioEconomic Classification (NS-SEC) system, ${ }^{18}$ which is an occupation-based classification of SES widely used in the UK. Specifically, we used three categories, the ordinal version of NS-SEC, with 'not-classified' as a fourth category. See online supplementary table S1 on how we aggregated NS-SEC classes from different surveys to the four categories used in this study.

\section{Physical activity scenarios}

\section{Travel data}

Background travel data for England were obtained from the National Travel Survey (NTS). ${ }^{19}$ The NTS is a rolling repeat cross-sectional annual household survey that records individual travel behaviour based on face-to-face interviews and a 7-day self-reported travel diary. Annual sample size is 16000 individuals in 7000 households.

We obtained the year 2002-2012 NTS data from the UK data Service, from which years 2010-2012 data was extracted for this analysis. ${ }^{19}$ For each person (62 070), we extracted the age, gender, NS-SEC and travel mode data. We then allocated individuals to five age groups, two genders and four NS-SEC groups (see online supplementary table S1). We excluded individuals aged $<20$ and over 69 years, which gave a total of 39122 individuals for the travel study sample.

\section{Travel scenarios}

For the physical activity scenarios, we replaced different shares of existing trips done by car with cycling, taking into account trip stage distances for trips involving travelling in a car (table 2). The NTS defines a trip as 'a one-way course of travel having a single main purpose'. A trip can have multiple stages and new stages are defined when 'there is a change in the form of transport or when there is a change of vehicle requiring a separate ticket'. ${ }^{20}$ The scenarios were created so that for each trip stage distance $(<1,<2,<3,<5,<8$ miles $)$ the total miles per person were recorded and then summarised for each scenario. The respective scenarios were labelled as
A-E, so A ( $<1$ mile) to $\mathrm{E}$ ( $<8$ miles; table 2$)$. The car trip stages included any trips by 'private car', as defined in the NTS. Only stages where the person was the driver were taken into account.

For cycling we obtained duration and distance of each stage done by bike, from which we calculated average cycling speed by age and gender (see online supplementary figure $\mathrm{S} 1$ ). On the basis of this, we calculated increases in cycling time by dividing the miles travelled by car (from A to $\mathrm{E}$ above) by the average cycling speed. We could therefore estimate the increase in cycling time (hours) per week, if all stages of a particular trip stage length travelled by car were to be substituted by cycling.

\section{Background physical activity data}

The DRF for physical activity is non-linear. ${ }^{21-23}$ To estimate health benefits of increased cycling, we needed to take into account background physical activity of the target population. Background physical activity data were obtained from the 2012 Health Survey for England $(\mathrm{HSE})^{24}$-an annual survey that monitors the health of the English population. The year 2012 data were obtained because it is the latest HSE survey with a physical activity focus.

The HSE provided us with activity data on 'walking' and 'doing sport' by age, gender, NS-SEC and duration per week for a total of 6436 individuals aged 20-69 years. For each individual, we calculated background physical activity levels by converting 'time walking' and 'doing sport' to metabolic equivalent of task (METs) hours. METs are a measure of intensity of physical activity that can be used to aggregate different activities to one physical activity unit. $^{25}$ One MET refers to the energy cost of being seated (resting). Total MET hours per week can be calculated by multiplying the time spent on different physical activities with the average MET of that activity. In this study, we used marginal METs (mMETs) which refers to energy use above rest. mMETs are calculated by subtracting 1 from the MET 
Table 2 Description of scenarios and anticipated changes in health, GHG emissions and consumer costs

\begin{tabular}{|c|c|c|c|c|}
\hline $\begin{array}{l}\text { Name of the } \\
\text { scenario }\end{array}$ & Description of scenario & Health & $\begin{array}{l}\text { GHG } \\
\text { emissions }\end{array}$ & $\begin{array}{l}\text { Consumer } \\
\text { cost }\end{array}$ \\
\hline $\mathrm{BAU}$ & BAU. Background situation & 0 & 0 & 0 \\
\hline A & All car stages 1 mile or shorter are replaced with cycling & + & + & + \\
\hline B & All car stages 2 miles or less long are replaced with cycling & + & + & + \\
\hline $\mathrm{C}$ & All car stages 3 miles or less long are replaced with cycling & + & + & + \\
\hline $\mathrm{D}$ & All car stages 5 miles or less long are replaced with cycling & + & + & + \\
\hline $\mathrm{E}$ & All car stages 8 miles or less long are replaced with cycling & + & + & + \\
\hline $\mathrm{F}$ & All people eat 1 portion of fruit and vegetables more per day & + & - & - \\
\hline $\mathrm{G}$ & All people eat 2 portions of fruit and vegetables more per day & + & - & - \\
\hline $\mathrm{H}$ & All people eat 3 portions of fruit and vegetables more per day & + & - & - \\
\hline I & All people eat 4 portions of fruit and vegetables more per day & + & - & - \\
\hline $\mathrm{J}$ & All people eat 5 portions of fruit and vegetables more per day & + & - & - \\
\hline $\mathrm{K}$ & All people eat at least 5 portions of fruit and vegetables per day & + & - & - \\
\hline
\end{tabular}

rate of different activities and hence give greater relative weight to more intensive activity.

From the HSE we also obtained activity time for walking and 10 different sports (see online supplementary table S2). Average mMETs for walking and each different sport were selected from the Compendium of Physical Activities 2011 database ${ }^{25}$ by comparing the definition of the activities in HSE 2012 to the description of activities in the Compendium. To account for uncertainty in the estimates, we assumed a $\pm 25 \%$ uncertainty range around the average mMETs for each activity.

\section{Integration of travel and health data}

Individuals from the NTS and HSE data sets were integrated randomly to create a synthetic population for further analysis (figure 1). The integration was done so that a random person in the same age group (5), gender (2) and SES (4) was drawn separately from the NTS and the HSE and then matched together to create a synthetic person with a background travel pattern based on the NTS and a background non-travel physical activity based on the HSE. For each age, gender and socioeconomic group, 1000 random individuals were drawn from the NTS and the HSE. All further calculations were based on this synthetic population. Comparison of the synthetic population with the original survey data showed that average input values had about $\pm 5 \%$ differences between the synthetic population and the survey data samples for most age, gender and NS-SEC groups (see online supplementary table S3).

\section{Fuel cost and GHG emissions}

Fuel consumption savings as a result of substituting car travel with cycling were estimated based on the tailpipe (exhaust) carbon dioxide $\left(\mathrm{CO}_{2}\right)$ emissions factors for petrol and diesel cars in the UK (see online supplementary table $\mathrm{S} 4$ ). Values for $\mathrm{CO}_{2}$ were obtained from the Greenhouse Gas Conversion Factor Repository ${ }^{26}$ and the average $\mathrm{CO}_{2}$ content per fuel from UK Energy Statistics. ${ }^{27}$ By combining this information with the average fuel price ${ }^{28}$ and with the proportion of car fleet between petrol and diesel cars ${ }^{29}$ we estimated that the average fuel cost $0.19 £ /$ mile (at 2015 prices; see online supplementary table S3). The Automobile Association of the UK estimated that the running costs of petrol and diesel cars vary from 0.19 to $0.29 £ / \mathrm{mile}$ and 0.17 to $0.28 £ /$ mile, respectively. Therefore, our estimate for fuel costs can be considered a conservative estimate of the running costs of a car. Given the wide distribution of tailpipe $\mathrm{CO}_{2}$ emissions from cars and the variability in fuel costs across time and space, we assumed a $\pm 50 \%$ uncertainty around these average estimates.

Similar to the above, changes in GHG emissions for the different scenarios were calculated based on the Greenhouse Gas Conversion Factor Repository. ${ }^{26}$ The GHG emission data were based on carbon dioxide equivalent $\left(\mathrm{CO}_{2} \mathrm{e}\right)$ emissions factors that take into account all transport-related GHG emissions. The average $\mathrm{CO}_{2} \mathrm{e}$ emission factor for cars was assumed to be $0.32 \mathrm{~kg} \mathrm{CO} \mathrm{CO}_{2} \mathrm{e} /$ mile. We assumed a $\pm 25 \%$ uncertainty for this emission factor in our sensitivity analyses. National $\mathrm{CO}_{2} \mathrm{e}$ emission reduction was calculated by estimating the average reduction of car driving per person in different scenarios and then multiplying this with the study population by age, sex and NS-SEC (table 1 ).

\section{Diet scenarios}

Background F\&V data

Background $\mathrm{F} \& \mathrm{~V}$ data were obtained from the rolling programme of the National Diet and Nutrition Survey (NDNS).$^{30}$ The NDNS collects nationally representative data on food consumed by individuals and covers all 
four countries in the UK. We used all available data for adults aged between 20 and 69 years $(n=1767)$. From the NDNS we extracted the background F\&V consumption per person, stratified by age, gender and NS-SEC. We followed the NDNS approach in counting a single portion of $\mathrm{F} \& \mathrm{~V}$ as $80 \mathrm{~g}$ of consumed mass.

\section{F\&V scenarios}

The first five diet scenarios (F-J) assumed that everyone in the study population would consume $1,2,3,4$ or 5 portions of F\&V more per day, respectively (table 2). In scenario $\mathrm{K}$, we assumed that everyone who does not consume five portions of $\mathrm{F} \& \mathrm{~V}$ per day would increase their consumption to five portions per day. This represents a scenario where everyone in the study population would eat five portions a day or more. The remainder of the diet was assumed to stay unchanged, therefore implying that any additional $\mathrm{F} \& \mathrm{~V}$ intake was not replacing other food items.

\section{F\&V costs and GHG emissions}

One portion of $\mathrm{F} \& \mathrm{~V}$ was assumed to cost $£ 0.22$, based on Jones and Monsivais. ${ }^{31}$ In that study, the average costs of $\mathrm{F} \& \mathrm{~V}$ were predicted by combining food price information with the food consumption information from NDNS. Thus, the costs of F\&V reflect the average costs of F\&V when taking into account how much and which F\&Vs are eaten in the UK. To account for uncertainty in portion cost, we assumed a $\pm 25 \%$ sensitivity range around the average cost of one $\mathrm{F} \& \mathrm{~V}$ portion.

The embedded GHG emissions of $\mathrm{F} \& \mathrm{~V}$ were assumed to be $0.086 \mathrm{~kg} \mathrm{CO}_{2} \mathrm{e} /$ portion (for fruit) and $0.166 \mathrm{~kg}$ $\mathrm{CO}_{2} \mathrm{e}$ /portion (for vegetables). Emissions were calculated by combining the food item-specific GHG emissions from Audsley et $a \hat{l}^{2}$ with the dietary intake information from the European Prospective Investigation into Cancer and Nutrition-Norfolk, UK cohort. ${ }^{33}$ A similar method was used by Briggs $e t a l^{34}$ and Scarborough et al. ${ }^{35}$ The change in national $\mathrm{CO}_{2} \mathrm{e}$ emissions was estimated by first calculating the per person increase of portions by age, sex and NS-SEC, and then multiplying the average $\mathrm{CO}_{2} \mathrm{e}$ increase per person with the background population (table 1).

\section{DRFs and background mortality}

Changes in all-cause mortality were estimated for physical activity and F\&V consumption. For physical activity we obtained DRFs from a systematic review and meta-analysis by Woodcock et $a .^{21}$ We used relative risk (RR) values of 0.81 (95\% CI 0.77 to 0.85$)$ comparing 8.6 mMEThours/week against no activity. Woodcock et $a l^{21}$ reported several different shapes of DRFs varying from nearly linear to non-linear ones. We assumed that the shape of the DRF is uncertain and varied by power log between 0.25 (non-linear) and 1.00 (linear), with 0.5 as a central estimate.

For F\&V consumption we adopted DRFs from the dose-response meta-analysis by Wang et $a l^{\beta 6}$ who pooled results from seven epidemiological cohort studies that had examined associations between F\&V consumption and all-cause mortality. They estimated both linear and non-linear DRF for F\&V consumption. In this study, we used the non-linear DRF. Compared with people who eat zero portions of $\mathrm{F} \& \mathrm{~V}$ per day, the estimated HRs for all-cause mortality were $0.92,0.85,0.79,0.76,0.74$ and 0.74 for one, two, three, four, five and six or more portions of $\mathrm{F} \& \mathrm{~V}$ per day, respectively. We used these HRs to estimate the mortality change after increased $\mathrm{F} \& \mathrm{~V}$ consumption. Thus, we assumed that after the sixth portion of $\mathrm{F} \& \mathrm{~V}$ per day there would be no further benefit.

The contribution of physical activity and F\&V to allcause mortality was calculated by applying the following equation:

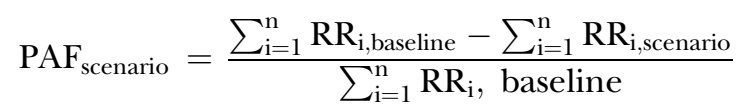

Where PAF is the population attributable fraction, $R R_{i, b a s e l i n e}$ is the RR at the exposure level $i$ in baseline scenario, $R_{i, \text { scenario }}$ is the $R R$ at the exposure level $i$ in scenario and $\mathrm{n}$ is the number of people affected by the scenario.

The change in all-cause mortality by age, sex and NS-SEC was calculated by multiplying the PAFs with the background mortality. Background mortality for two calendar years for the population of England and Wales was obtained from the ad hoc database of the Office for National Statistics. ${ }^{37}$ The number of deaths per year for the study population was estimated from these data by adjusting the number of deaths for England and Wales with English mortality counts for the year $2011,{ }^{38}$ and by halving the values to calculate mortality counts for 1 year. Adjusted mortality data for the study population are presented in table 3 .

\section{Implementation of the model}

The model was implemented using the Monte Caro simulation program Analytica V.4.6 (http://www.lumina. com) running 1000 iterations. Monte Carlo simulation was used to predict $95 \%$ credible intervals for each uncertain output variable.

\section{RESULTS}

The health benefits for the different scenarios varied from 75 (95\% credible interval 47 to 113$)$ deaths avoided per year (scenario A) to 6187 (95\% CI -2430 to 14836 ) deaths avoided per year (scenario J; figure 2 , see online supplementary table S5 in supplementary material for the numerical values). In all scenarios, the number of deaths averted was higher for men. In physical activity scenarios, women increased cycling more than men (see online supplementary figure S2) while the background mortality was higher for men (table 3 ). When combined, the overall premature deaths averted was slightly higher for men. For the diet scenarios $(\mathrm{F}-\mathrm{J})$, both genders increased $\mathrm{F} \& \mathrm{~V}$ consumption by one or 
Table 3 Percentage of deaths by age, sex and NS-SEC for England (total number of deaths 103843 cases per year)

\begin{tabular}{|c|c|c|c|c|c|c|}
\hline & 20-29 & $30-39$ & $40-49$ & $50-59$ & $60-69$ & Sum \\
\hline \multicolumn{7}{|l|}{ Female } \\
\hline Higher managerial, administrative and professional occupations & $0.2 \%$ & $0.5 \%$ & $1.6 \%$ & $3.5 \%$ & $6.9 \%$ & $12.6 \%$ \\
\hline Intermediate occupations & $0.1 \%$ & $0.3 \%$ & $0.9 \%$ & $2.0 \%$ & $5.0 \%$ & $8.2 \%$ \\
\hline Routine and manual occupations & $0.2 \%$ & $0.4 \%$ & $1.4 \%$ & $3.2 \%$ & $8.1 \%$ & $13.4 \%$ \\
\hline *Never worked and long-term unemployed & $0.4 \%$ & $0.6 \%$ & $1.2 \%$ & $1.6 \%$ & $1.8 \%$ & $5.6 \%$ \\
\hline Sum & $0.9 \%$ & $1.9 \%$ & $5.0 \%$ & $10.2 \%$ & $21.8 \%$ & $39.7 \%$ \\
\hline \multicolumn{7}{|l|}{ Male } \\
\hline Higher managerial, administrative and professional occupations & $0.2 \%$ & $0.6 \%$ & $1.6 \%$ & $3.6 \%$ & $7.8 \%$ & $13.8 \%$ \\
\hline Intermediate occupations & $0.2 \%$ & $0.5 \%$ & $1.2 \%$ & $2.8 \%$ & $6.8 \%$ & $11.4 \%$ \\
\hline Routine and manual occupations & $0.7 \%$ & $1.3 \%$ & $3.1 \%$ & $6.8 \%$ & $15.8 \%$ & $27.8 \%$ \\
\hline *Never worked and long-term unemployed & $0.8 \%$ & $1.0 \%$ & $1.7 \%$ & $1.9 \%$ & $1.8 \%$ & $7.2 \%$ \\
\hline Sum & $2.0 \%$ & $3.4 \%$ & $7.7 \%$ & $15.0 \%$ & $32.2 \%$ & $60.3 \%$ \\
\hline
\end{tabular}

Data were obtained from the Office for National Statistics ad hoc data service for England and Wales, and were adjusted for the population of England with the mortality numbers per age and gender ${ }^{37}$.

NS-SEC, National Statistics Socio-Economic Classification.

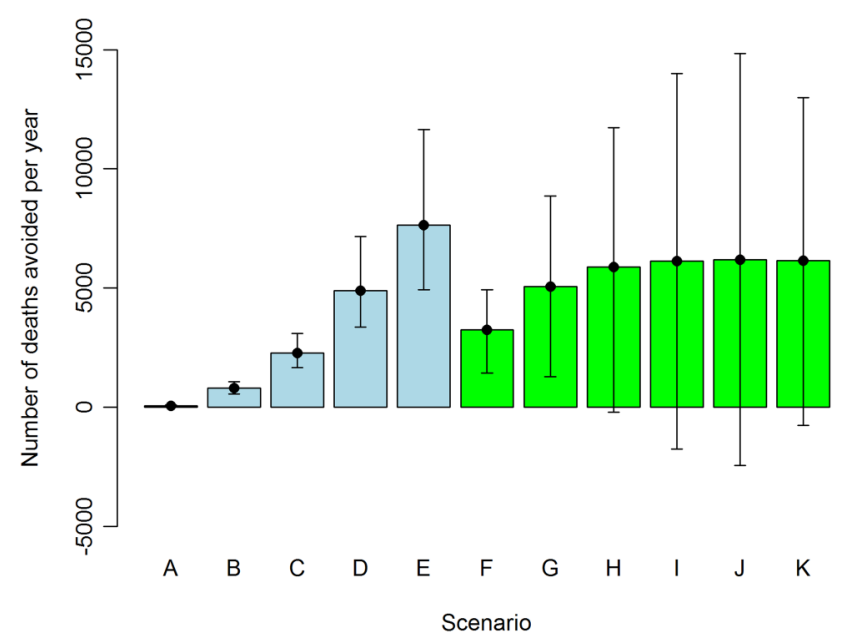

Figure 2 Avoidable deaths per year (mean and 95\% credible interval) in England for different scenarios. See table 2 for description of scenarios and online supplementary table S4 for numerical values.

more portions per day and this led to a higher mortality decrease for men than for women (figure 2). Also, in scenario $\mathrm{K}$, where the portion increase depended on background $\mathrm{F} \& \mathrm{~V}$ consumption, men benefited more than women.

About $73 \%$ of people increased $\mathrm{F} \& \mathrm{~V}$ consumption in scenario $\mathrm{K}$. The percentage of population changing their physical activity was $13 \%, 33 \%, 43 \%, 51 \%$ and $55 \%$ for scenarios A-E, respectively. The mean increase in cycling time among those changing their behaviour ranged from 0.2 to 5.0 hours/week (see online supplementary figure S2). This had a noticeable impact on population physical activity. In the baseline case, $44 \%$ of the study population were engaged in at least $150 \mathrm{~min}$ of physical activity per week with medium intensity (8.75 mMEThours/week); in scenario E, this increased to $67 \%$ (see online supplementary figure S3). About $30 \%$ of the population were achieving $300 \mathrm{~min}$ of

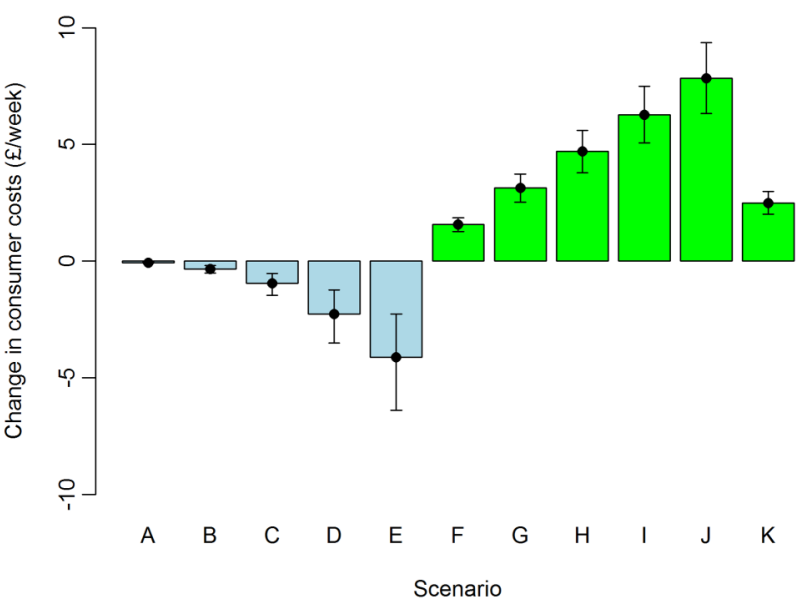

Figure 3 Change in consumer costs in different scenarios (mean and 95\% credible interval).

medium intensity physical activity at baseline; in scenario $\mathrm{E}$, this increased to $52 \%$ (see online supplementary figure S3).

\section{Estimated health impact of scenarios by SES}

Online supplementary figure S4 shows the percentage changes in all-cause mortality for different scenarios and socioeconomic groups, with deaths avoided shown in online supplementary figure S5. For the physical activity scenarios (A-E), the percentage decrease in mortality was similar across the NS-SEC groups for scenarios A-C, but in scenarios $\mathrm{D}$ and $\mathrm{E}$ the lowest NS-SEC group (group 3, routine and manual occupations) showed smaller benefits than the rest. In all physical activity scenarios, people outside the NS-SEC classification showed smaller benefits than people within the classification. The lowest NS-SEC group and people outside the NS-SEC classification benefited most in the diet scenarios (F-K). Importantly, over half of the avoidable deaths would occur in the lowest NS-SEC group for all 
diet scenarios (group 3, routine and manual occupations; see online supplementary figure S5).

\section{Costs}

Figure 3 provides changes in weekly average consumer costs per person for scenarios A-K, showing a range of positive and negative outcomes. Scenario E, for instance, was estimated to decrease per person costs of the study population by $£ 4.12$ (95\% CI £2.26 to £6.38) per person per week; and scenario J was estimated to increase costs by $£ 7.84$ (95\% CI $£ 6.32$ to $£ 9.36$ ) per person per week (see online supplementary table S5). These represent $15 \%$ and $34 \%$ changes in mean transport (£27.38) and food and non-alcoholic drinks (£22.83) costs per week, respectively $^{12}$ (see online supplementary table S6). For the physical activity scenarios (A-E), fuel cost savings were highest among the highest NS-SEC group, with changes proportionally similar between the different NS-SEC groups. For diet scenario K, the cost increases were highest for the lowest NS-SEC group ( $£ 2.98$ per person per week) and lowest for the highest NS-SEC group ( $£ 1.99$ per person per week). For scenario J, the lowest and highest NS-SEC groups increased food and alcoholic drinks costs by $39 \%$ and $23 \%$, respectively, indicating significant socioeconomic differences in the proportional costs between scenarios.

\section{GHG emissions}

Changes in GHG emissions in different scenarios are presented in figure 4. The $\mathrm{CO}_{2} \mathrm{e}$ emissions reductions due to decreased car use were 67 times higher in scenario $\mathrm{E}$ when compared with scenario A. Owing to increased consumption of $\mathrm{F} \& \mathrm{~V}$, scenario $\mathrm{J}$ gave five times higher $\mathrm{CO}_{2} \mathrm{e}$ emissions than scenario $\mathrm{F}$. When compared with annual $\mathrm{CO}_{2} \mathrm{e}$ emissions from passenger cars in England (56.5 $\mathrm{MtCO}_{2} \mathrm{e} /$ year, in $2012^{39}$ ), total emissions from cars would drop by between $0.3 \%$ (scenario A) and 19\% (scenario E). The diet scenarios were

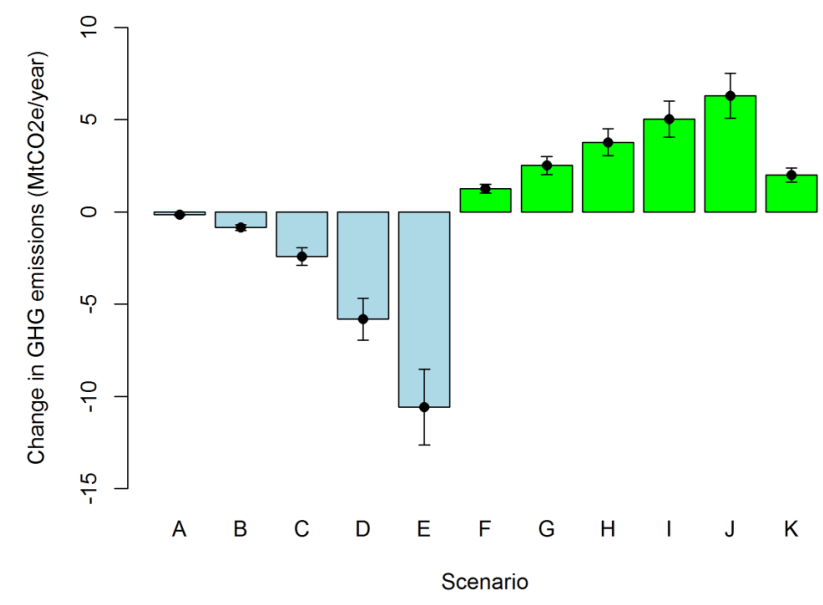

Figure 4 Change in $\mathrm{GHG}$ emissions ( $\mathrm{MtCO}_{2} \mathrm{e} /$ year) in different scenarios (mean and $95 \%$ credible interval). GHG, greenhouse gas; $\mathrm{MtCO}_{2} \mathrm{e}$, million tons of carbon dioxide equivalent. equivalent to an increase in GHG emissions from agriculture in England (which were $28.27 \mathrm{MtCO}_{2} \mathrm{e}$ /year in $2012^{39}$ ) of between $4.4 \%$ (scenario F) and 22\% (scenario J). In comparison, scenario $\mathrm{K}$ showed an increase in GHG emissions of $7.1 \%$.

\section{DISCUSSION}

This study simultaneously estimated the health effects, consumer costs and GHG emission changes of several physical activity and diet scenarios for the working age population of England. While the direction of the changes was perhaps as expected, this study allowed us, for the first time, to quantify the magnitude of the impacts across different outcomes and population groups. Replacing short car trips with cycling and increasing consumption of $\mathrm{F} \& \mathrm{~V}$ would create large health benefits for the population. While replacing short car trips with cycling would benefit more people with high SES, increasing consumption of F\&V would benefit more people with lower SES. Both would have significant impacts on consumer costs so that diet scenarios would increase food and non-alcoholic drinks costs for people in low SES groups, whereas for the physical activity scenarios cost differences between SES groups are smaller. Both physical activity and diet scenarios implied significant changes to transport and agricultural GHG emissions in England.

\section{Meaning of the study: possible explanations and} implications for clinicians and policymakers

Increasing physical activity (scenarios $\mathrm{A}-\mathrm{E}$ ) and $\mathrm{F} \& \mathrm{~V}$ consumption (scenarios F-K) would have large health benefits in their own right. What this study added is quantifying and comparing those benefits against each other. Even relatively small changes in travel behaviour, such as replacing the shortest $(<1$ mile long) car trips with cycling (scenario A), would have modest health benefits, with 75 premature deaths avoided per year (figure 2). The diet scenarios showed even greater potential for health benefits, with $\sim 3000$ deaths avoided per year if people would eat one portion of $\mathrm{F} \& \mathrm{~V}$ more per day (scenario F, figure 2). By quantifying benefits of such scenarios, this study provides information that can be used in cost-benefit studies that assess health and diet interventions.

We also quantified the health and cost changes between socioeconomic groups. In physical activity scenarios (A-E), population health was improved most for the people in the highest SES group (see online supplementary figures S4 and S5). Since more people of higher SES make short car trips, more people benefit from the shift to active modes (see online supplementary figure S6). Thus, replacing car trips with cycling would improve health overall but would not reduce health inequalities. It is important to note that we have not modelled an increase in cycling per se but a shift from cars to bikes. The results might have been 
different if we would have considered a potential shift from buses to cycling, or the potential for new cycling trips for those who do not have access to a car, for example, if cycling helped access new employment opportunities.

The diet scenarios showed great potential for reducing health inequalities by benefiting most people in low SES (see online supplementary figures S4 and S5). In all diet scenarios $(\mathrm{F}-\mathrm{K})$, approximately half of all the deaths avoided were in the lowest SES group. However, people in the lowest SES group would have a significant percentage increase in their food and non-alcoholic drinks costs (see online supplementary table S6). This suggests that affordability or compensation needs to be considered for interventions aiming to increase $\mathrm{F} \& \mathrm{~V}$ consumption.

The story was more straightforward for changes in GHG emissions (figure 4), with physical activity scenarios decreasing transport-related GHG emissions and diet scenarios increasing emissions by several percentage points over baseline GHG emissions from transport and agriculture. This has obvious implications for designing integrated health and climate change mitigation policies, further contributing to the debate about how to achieve 'co-benefits' across outcomes and policy objectives.

\section{Strengths and limitations}

The strength of our study is the combination of health, consumer cost and GHG emission effects of physical activity and diet scenarios to one assessment. We could show health and consumer cost effects by age, gender and SES to indicate which scenarios would most likely reduce health inequalities, and what would be the likely magnitude of the impact. To the best of our knowledge, this is the first study that has integrated such a variety of pathways (physical activity, diet) to outcomes (health, cost, GHG emissions).

This study took advantage of the good-quality survey data routinely collected in England from health, transport and diet (figure 1). On the basis of these data, we could create individual-based scenarios where the changes in physical activity and diet are calculated on an individual level, rather than based on population averages. For physical activity and F\&V consumption, the DRF for all-cause mortality is non-linear and assessing the changes in health on an individual level allows us to better take into account these non-linearities. Also, by using individual-level data, we could estimate costs per person, rather than average changes.

To combine and quantify all the outcomes, we needed to make some simplifications, with potential impacts to results.

First, for the diet scenarios, we only took into account increase in $\mathrm{F} \& \mathrm{~V}$ consumption independent of the possible other changes in diet. If increases in F\&V consumption are not compensated for by reductions in other areas, body mass index (BMI) would increase, leading to negative health effects. If there were compensatory energy intake reductions in the consumption of other food groups, this could have positive or negative changes in health, depending on what food items are compensated. For example, a shift from meat consumption to $\mathrm{F} \& \mathrm{~V}$ could reduce GHG emissions and consumer costs, while a reduction in sugar consumption would benefit health but have little effect on GHG emissions or cost. ${ }^{33}$

To predict these changes, some modelling studies, such as Nnoaham et al, ${ }^{40}$ have predicted changes in multiple food groups. In that study, one of the scenarios (scenario 4) predicted an $\sim 10 \%$ increase in $\mathrm{F} \& \mathrm{~V}$ consumption with $1 \%$ or less changes in calories, saturated fat and salt intake. The health benefits of this scenario were 3700 deaths avoided with only minor negative health effects related to obesity. This indicates that the health effects were mainly due to changes in F\&V consumption and not due to BMI.

Second, we based our background travel data on stages of the trips. This means that we did not take into account journeys that consisted of several stages (eg, driving and walking). This will add uncertainty to our results since not all the stages can be cycled if they are part of a multistage journey. However, since our purpose was to estimate creditable upper bound health benefits of different scenarios, rather than effects that can be achieved, we consider this simplification justifiable.

Third, for the physical activity scenarios, we took into account only the benefits of physical activity without consideration of risks. Several other health impact assessment studies have examined health effects of mode shift from motorised transport to active transport (walking, cycling) in the UK and elsewhere by taking into account physical activity, air pollution and injury risks. ${ }^{4}$ The general conclusion from these studies has been that physical activity benefits are larger than the risks posed by air pollution and injuries. ${ }^{41} 42 \mathrm{~A}$ recent study that compared physical activity benefits with air pollution risks has confirmed that with the air pollution levels in England, individual benefits from physical activity will be substantially higher than harms. ${ }^{43}$ Thus, we assumed that our results would be similar even if the injury and air pollution risks would be taken into account.

Fourth, the diet scenarios result in changes to all people consuming fewer than six and, in one case, five portions of $\mathrm{F} \& \mathrm{~V}$ per day, while the physical activity scenarios affect only those doing car trips shorter than 1-8 miles. If we had devised a physical activity scenario that affected all those doing less than the recommended levels, then the benefits would have been larger. However, replacing short car trips with cycling is often cited as a mechanism for increasing population levels of physical activity and provides a more interesting comparison than a more abstract scenario. Cycling could also come from other modes than driving. If cycling replaces other motorised modes, then physical activity benefits 
would be greater and spread across a wider demographic, providing more equitable benefits. On the other hand, if cycling would replace walking, then physical activity and associated benefits would be smaller.

Fifth, in diet scenarios, we used average $\mathrm{CO}_{2} \mathrm{e}$ emission factors based on the food items currently consumed in England. However, there exists wide variation in average $\mathrm{CO}_{2} \mathrm{e}$ emissions per different food items and the actual increase of the emissions would vary a lot between different food items. For example, by following Audsley $e t a l$, the emission factor for cabbages produced in the UK would be $0.0176 \mathrm{~kg} \mathrm{CO} 2 \mathrm{e} /$ portion (five times smaller than the emission factor used in our study). On the other scale are beans produced outside Europe, with an emission factor of $0.816 \mathrm{~kg} \mathrm{CO}_{2} \mathrm{e} /$ portion (6.5 times higher than the emission factor used in this study). Thus, the environmental impact could be improved by focusing on increasing uptake of lower emission F\&Vs.

\section{Comparison to other studies, discussing important differences in results}

We modelled the health effects directly from physical activity and $\mathrm{F} \& \mathrm{~V}$ consumption to health outcomes without intermediate risk factors. For example Cecchini et $a l^{44}$ estimated health effects of physical activity and diet scenarios through one intermediate risk factor (BMI), and through three proximal risk factors (blood pressure, cholesterol, glycaemia). The PRIME (Preventable Risk Integrated ModE) model ${ }^{45}$ estimates physical activity and diet risks both directly and through BMI. On the basis of the comparison of our results to the apple per day scenario, ${ }^{7}$ calculated with the PRIME model and described in greater detail in online supplementary material, our estimates are of a similar magnitude but smaller, providing some cross-model validation of the results.

The results of physical activity scenarios (A-E) are similar to those made in a previous study for Barcelona, Spain, ${ }^{13}$ but much smaller than similar study in New Zealand $^{14}$ (see online supplementary material for details). Both of these studies adopted the linear DRFs from the WHO Health Economic Assessment Tool (HEAT) to estimate health benefits of physical activity. ${ }^{46}$ Earlier studies have found that linear DRFs from HEAT suggest larger health benefits than the non-linear functions applied in our study, but this finding is likely to be scenario specific. ${ }^{47}$

Diet scenario $(\mathrm{F}-\mathrm{K})$ results are smaller than the two UK modelling studies that have examined health benefits of eating more apples ${ }^{7}$ or ${\mathrm{F} \& \mathrm{~V}^{8}}^{8}$ (see online supplementary material for details). Both of these studies included an older population than did our study and this might explain the smaller health benefits in our study. In our study, diet scenarios had also significant SES differences in proportional costs indicating that people in low SES might have financial difficulties to increase $\mathrm{F} \& \mathrm{~V}$ consumption. A recent review of dietary interventions concluded that price interventions appear to decrease inequalities. ${ }^{10}$

A previous UK study estimated $\mathrm{CO}_{2}$ emissions of transport by purpose and the distance of the trips. ${ }^{13}$ In that study, $21 \%$ of the transport-related $\mathrm{CO}_{2}$ emissions were from trips $<5$ miles long. ${ }^{13}$ In our study, scenario $\mathrm{D}$ was assumed to reduce $\mathrm{CO}_{2} \mathrm{e}$ emissions by $5.8 \mathrm{MtCO}_{2} \mathrm{e}$ /year (figure 4), which represents $10.3 \%$ of total cars-related and taxis-related $\mathrm{CO}_{2} \mathrm{e}$ emissions in England in 2012. A number of earlier studies have also observed highly unequal distributions of $\mathrm{CO}_{2}$ emissions from motorised travel, ${ }^{48-50}$ with the top fifth of the population generally producing more than three-fifths of the emissions. In our study, the $\mathrm{CO}_{2} \mathrm{e}$ emission reductions were highest among the highest NS-SEC groups and lowest in the 'never worked group' indicating SES differences in the GHG emissions.

For diet, previous UK modelling study combining health and climate effects concluded that adopting diets with low GHG emissions would provide large health co-benefits through changes in fruit, vegetable, red meat and processed meat consumption. ${ }^{51}$ That study optimised GHG emission reductions by taking into account potential acceptance of the new diet and dietary recommendations from the WHO, and estimate health as co-benefit following the climate friendlier diet. This shows that an increase in $\mathrm{F} \& \mathrm{~V}$ consumption can be part of a decrease in overall GHG emissions from food production if other parts of the diet change sufficiently.

\section{Unanswered questions and future research}

Our scenarios assumed hypothetical change in the physical activity and diet behaviour without consideration of how such changes could be achieved in a population. The next challenge for impact assessment research is to predict how individual actions or programmes would change the behaviour of the population, and what consequences these changes would have. For example, a large body of evidence indicates that providing safe, comfortable and direct routes for cycling to popular destinations is the most effective method for achieving mass cycling. This evidence is based on the experience of high cycling countries, ${ }^{52}{ }^{53}$ stated preferences on infrastructure and fear of motor traffic,${ }^{54}$ studies on the injury risk reductions on protected infrastructure, ${ }^{55}$ and is beginning to be supported by evidence from natural experiment studies. ${ }^{56}$

For diet, the econometric analysis of the UK 5 a day marketing campaign, aimed at increasing F\&V consumption in the population, concluded that the campaign increased average $\mathrm{F} \& \mathrm{~V}$ consumption by 0.3 portions per day ${ }^{57} \mathrm{~A}$ meta-analysis of randomised controlled trials in retirement age adults increased $\mathrm{F} \& \mathrm{~V}$ intake by approximately one portion per day both the short term (less than a year) and long term (more than a year). ${ }^{58}$ Translating this kind of evidence for impact assessment is challenging, but required, to estimate the likely effectiveness of different interventions. 


\section{CONCLUSIONS}

We estimated health benefits of physical activity (mode shift from car to bicycle) and diet (eating more $\mathrm{F} \& \mathrm{~V}$ ) related scenarios for the working age population of England. We also estimate changes in GHG emissions and costs. We found out that both replacing short car trips with cycling and increasing consumption of $\mathrm{F} \& \mathrm{~V}$ would have large health benefits for the population. Physical activity scenarios benefited most people with high NS-SEC status, and diet scenarios people with low NS-SEC. Since the physical activity scenarios lowered costs and the diet ones increased them, this means that costs were increased most for people of lower SES and reduced most for people of high SES. These results give quantitative information on potential health, GHG emission and consumer cost changes that physical activity-related transport scenario and F\&V-related diet scenarios could achieve at the population level.

Twitter Follow Marko Tainio @MarkoTainio

Acknowledgements The authors thank Alvaro Ullrich from the MRC Epidemiology Unit, University of Cambridge for preparing the background travel data. The authors would like to acknowledge UK Data Archive, NatCen Social Research and University College London for providing the Health Survey for England 2012 data; UK Data Archive, NatCen Social Research, MRC Human Nutrition Research and University College London for providing National Diet and Nutrition Survey Years 1-4 data; and UK Data Archive, Department for Transport and National Centre for Social Research for providing the National Travel Survey, 2002-2012 data. The authors would also like to thank the reviewers, Professor Anil Markandya and Professor Alistair Woodward, for their valuable comments.

Contributors All authors made substantial contributions to the conception and design of the study. JW and PM had the original idea of the study. NJ prepared the diet data. MT prepared the physical activity data, did the modelling and drafted the first version of the manuscript. CB provided data to calculate greenhouse gas emissions and costs of driving. All authors drafted and critically revised the manuscript.

Funding MT, PM, NJ and JW were supported by the Centre for Diet and Activity Research (CEDAR), a UKCRC Public Health Research Centre of Excellence. Funding from the British Heart Foundation, Cancer Research UK, Economic and Social Research Council, Medical Research Council, the National Institute for Health Research, and the Wellcome Trust, under the auspices of the UK Clinical Research Collaboration, is gratefully acknowledged. JW is also supported by an MRC Population Health Scientist fellowship (grant number: MR/K021796/1). CB is supported by the UK Research Councils (grant number: EPSRC EP/L024756/1) as part of the Decision Making Theme of the UK Energy Research Centre Phase 3.

Competing interests MT reports grant from the Coca Cola Foundation outside the submitted work.

Provenance and peer review Not commissioned; externally peer reviewed.

Data sharing statement Anonymised, non-identifiable participant-level cross-sectional survey data are freely available for academic researchers and public health staff to download from the UK Data Service (www.ukdataservice. ac.uk). The key data sources used in this study were: SN: 6533 National Diet and Nutrition Survey Years 1-4, 2008/09-2011/12: http://discover. ukdataservice.ac.uk/catalogue/?sn=6533; SN: 7480 Health Survey for England 2012: http://discover.ukdataservice.ac.uk/catalogue?sn=7480; SN: 5340 National Travel Survey, 2002-2012: http://discover.ukdataservice.ac.uk/ catalogue?sn=5340.
Open Access This is an Open Access article distributed in accordance with the terms of the Creative Commons Attribution (CC BY 4.0) license, which permits others to distribute, remix, adapt and build upon this work, for commercial use, provided the original work is properly cited. See: http:// creativecommons.org/licenses/by/4.0/

\section{REFERENCES}

1. Forouzanfar MH, Alexander L, Anderson HR, et al., GBD 2013 Risk Factors Collaborators. Global, regional, and national comparative risk assessment of 79 behavioural, environmental and occupational, and metabolic risks or clusters of risks in 188 countries, 1990-2013: a systematic analysis for the Global Burden of Disease Study 2013. Lancet 2015;386:2287-323.

2. Newton JN, Briggs ADM, Murray CJL, et al. Changes in health in England, with analysis by English regions and areas of deprivation, 1990-2013: a systematic analysis for the Global Burden of Disease Study 2013. Lancet 2015;386:2257-74.

3. Rojas-Rueda D, de Nazelle A, Andersen ZJ, et al. Health impacts of active transportation in Europe. PLOS ONE 2016;11:e0149990.

4. Götschi T, Tainio M, Maizlish N, et al. Contrasts in active transport behaviour across four countries: How do they translate into public health benefits? Prev Med 2015;74:42-8.

5. Lindsay G, Macmillan A, Woodward A. Moving urban trips from cars to bicycles: Impact on health and emissions. Aust N Z J Public Health 2011;35:54-60.

6. Woodcock J, Tainio M, Cheshire J, et al. Health effects of the London bicycle sharing system: health impact modelling study. BMJ 2014;348:g425.

7. Briggs ADM, Mizdrak A, Scarborough P. A statin a day keeps the doctor away: comparative proverb assessment modelling study. BMJ Open 2013;347:f7267.

8. Möller $\mathrm{H}$, Dherani M, Harwood $\mathrm{C}$, et al. Health planning for the future: comparative risk assessment of five major lifestyle risk factors: evidence from the Wirral, UK. J Public Health 2012;34:430-7.

9. Roberts K, Cavill N, Hancock C, et al. Social and economic inequalities in diet and physical activity about Public Health England 2013. http://www.noo.org.uk/uploads/doc/vid_19253_Social_and economic inequalities in diet and physical activity 04.11.13.pdf

10. McGill R, Anwar E, Orton L, et al. Are interventions to promote healthy eating equally effective for all? Systematic review of socioeconomic inequalities in impact. BMC Public Health 2015;15:457.

11. Bull ER, Dombrowski SU, McCleary N, et al. Are interventions for low-income groups effective in changing healthy eating, physical activity and smoking behaviours? A systematic review and meta-analysis. BMJ Open 2014;4:e006046.

12. Daniel E, Keyse L, Skilton L, et al. Family spending, 2012 edition. Horsfield G, ed. 2012. http://webarchive.nationalarchives.gov.uk/ 20160105160709/http://ons.gov.uk/ons/rel/family-spending/ family-spending/family-spending-2012-edition/index.html

13. Department for Transport. Low carbon transport: a greener future. 2009:115 https://www.gov.uk/government/uploads/system/uploads/ attachment data/file/228897/7682.pdf

14. Department of Energy \& Climate Change. 2014 UK Greenhouse Gas Emissions, Final Figures. 2016. https://www.gov.uk/government/ uploads/system/uploads/attachment_data/file/496942/2014_Final_ Emissions_Statistics_Release.pdf

15. Jones NR V, Conklin Al, Suhrcke M, et al. The growing price gap between more and less healthy foods: analysis of a novel longitudinal UK dataset. PLOS ONE 2014;9:e109343.

16. Timmins KA, Hulme C, Cade JE. The monetary value of diets consumed by British adults: an exploration into sociodemographic differences in individual-level diet costs. Public Health Nutr 2015;18:151-9.

17. Office for National Statistics. СT0469-Sex by age by highest leve of qualification by NS-SeC. 2015. https://www.google.co.uk/url? $s a=t \& r c t=j \& q=\& e s r c=s \&$ source $=$ web\& $c d=1 \& v e d=0$ ahUKEwiy2sSR 5HSAhUFIcAKHaQuA88QFggcMAA\&url=https\%3A\%2F\%2Fwww. ons.gov.uk\%2Fons $\% 2$ Fabout-ons $\% 2 F b u s i n e s s-t r a n s p a r e n c y \%$ 2Ffreedom-of-information\%2Fwhat-can-i-request\%2Fpublished-adhoc-data\%2Fcensus\%2Fqualifications\%2Fct0469-2011-census. xls\&usg=AFQjCNFcbuQzb2foEZmQEzzl9Qq09fcrxw\&cad=rja

18. Office for National Statistics. Standard Occupational Classification 2010. Volume 3. The National Statistics Socio-economic Classification : (Rebased on the SOC2010) User Manual. 2010. http://www.ons.gov.uk/ons/guide-method/classifications/ current-standard-classifications/soc2010/soc2010-volume-3-nssec-rebased-on-soc2010-user-manual/index.html 
19. Department for Transport. National Travel Survey, 2002-2012. 8th edn. Colchester, Essex: UK Data Archive, 2014. http://discover. ukdataservice.ac.uk/catalogue/?sn $=5340$

20. Department for Transport. National Travel Survey: data extract user guide, 2002-2012. 8th edn, 2012.

21. Woodcock J, Franco OH, Orsini N, et al. Non-vigorous physical activity and all-cause mortality: systematic review and meta-analysis of cohort studies. Int J Epidemiol 2011;40:121-38.

22. Wen CP, Wai JPM, Tsai MK, et al. Minimum amount of physical activity for reduced mortality and extended life expectancy: a prospective cohort study. Lancet 2011;378:1244-53.

23. Kelly P, Kahlmeier S, Götschi T, et al. Systematic review and meta-analysis of reduction in all-cause mortality from walking and cycling and shape of dose response relationship. Int J Behav Nutr Phys Act 2014;11:132.

24. NatCen Social Research UCLD of E and PH. Health Survey for England, 2012. 2014. https://discover.ukdataservice.ac.uk/ Catalogue/?sn=7480\&type=Data catalogue

25. Ainsworth BE, Haskell WL, Herrmann SD, et al. 2011 Compendium of Physical Activities: a second update of codes and MET values. Med Sci Sports Exerc 2011;43:1575-81.

26. Department for Environment Food \& Rural Affairs (DEFRA). Greenhouse Gas Conversion Factor Repository. 2015. http://www. ukconversionfactorscarbonsmart.co.uk/

27. MacLeay I, Harris K, Annut A. Digest of United Kingdom Energy Statistics (DUKES) 2013;2013:1-268. https://www.gov.uk/ government/publications/digest-of-united-kingdom-energy-statisticsdukes-2013-printed-version-excluding-cover-pages

28. Department for Energy and Climate Change (DECC). Petrol and diesel prices and duties per litre in April: United Kingdom from 20001. 2015. https://www.gov.uk/government/uploads/system/ uploads/attachment_data/file/48915/env0105.xls

29. Department for Environment $F$ and RA (DEFRA). 2012 Guidelines to Defra/DECC's GHG. Conversion factors for company reporting: methodology paper for emission factors. Methodology Paper for Emission Factors. 2012. http://tinyurl.com/p46qukp

30. Public Health England. National Diet and Nutrition Survey Rolling Programme Years 1-4. 2014.

31. Jones NRV, Monsivais P. Comparing prices for food and diet research: the metric matters. J Hunger Environ Nutr 2016;248:1--12.

32. Audsley E, Brander M, Chatterton J, et al. How Low Can We Go? An assessment of greenhouse gas emissions from the UK food system and the scope for reduction by 2050. 2009. http://www.fcrn. org.uk/fcrn/publications/how-low-can-we-go

33. Monsivais P, Scarborough P, Lloyd T, et al. Greater accordance with the dietary approaches to stop hypertension dietary pattern is associated with lower diet-related greenhouse gas production but higher dietary costs in the United Kingdom. Am J Clin Nutr 2015:102:138-45.

34. Briggs ADM, Kehlbacher A, Tiffin R, et al. Assessing the impact on chronic disease of incorporating the societal cost of greenhouse gases into the price of food: an econometric and comparative risk assessment modelling study. BMJ Open 2013;3:e003543.

35. Scarborough P, Appleby PN, Mizdrak A, et al. Dietary greenhouse gas emissions of meat-eaters, fish-eaters, vegetarians and vegans in the UK. Clim Change 2014;125:179-92.

36. Wang $\mathrm{X}$, Ouyang $\mathrm{Y}$, Liu J, et al. Fruit and vegetable consumption and mortality from all causes, cardiovascular disease, and cancer: systematic review and dose-response meta-analysis of prospective cohort studies. BMJ 2014;349:94490.

37. Office for National Statistics. Mortality count by sex, five-year age bands, and by National Statistics Socio-economic Classification (NS-SEC) in England and Wales, in 2010 and 2011. 2014. http:// www.ons.gov.uk/ons/about-ons/business-transparency/ freedom-of-information/what-can-i-request/published-ad-hoc-data/ health/november-2014/mortality-count-by-sex--in-2010-and-2011.xls
38. Office for National Statistics. Mortality Statistics: deaths registered by area of usual residence, 2011 registrations. 2013. http://webarchive. nationalarchives.gov.uk/20160105160709/http://www.ons.gov.uk/ons/ $\mathrm{rel} / \mathrm{vsob} 1 /$ deaths-registered-area-usual-residence/2011/index.html

39. Salisbury E, Hampshire K, Brook R, et al. Greenhouse Gas Inventories for England, Scotland, Wales and Northern Ireland: 1990-2014. 2016:1-113. http://www.naei.org.uk/reports.php?list=GHG

40. Nnoaham KE, Sacks G, Rayner M, et al. Modelling income group differences in the health and economic impacts of targeted food taxes and subsidies. Int J Epidemiol 2009;38:1324-33.

41. Doorley R, Pakrashi V, Ghosh B. Quantifying the health impacts of active travel: assessment of methodologies. Transp Rev 2015;35:559-82.

42. Mueller N, Rojas-Rueda D, Cole-Hunter T, et al. Health impact assessment of active transportation: a systematic review. Prev Med 2015;76:103-14.

43. Tainio M, de Nazelle AJ, Götschi T, et al. Can air pollution negate the health benefits of cycling and walking? Preventive Medicine 2016;87:233-6.

44. Cecchini M, Sassi F, Lauer JA, et al. Tackling of unhealthy diets, physical inactivity, and obesity: health effects and cost-effectiveness. Lancet 2010;376:1775-84.

45. Scarborough P, Harrington RA, Mizdrak A, et al. The Preventable Risk Integrated ModEl and its use to estimate the health impact of public health policy scenarios. Scientifica (Cairo) 2014;2014:748750.

46. Kahlmeier S, Kelly P, Foster C, et al. Health economic assessment tools (HEAT) for walking and for cycling. Methods and user guide, 2014 update. Economic assessment of transport infrastructure and policies. Copenhagen, Denmark, 2014. http://www.euro.who.int/ data/assets/pdf_file/0010/256168/ECONOMIC-ASSESSMENT-OFTRANSPORT-INFRASTRUCTURE-AND-POLICIES.pdf?ua=1

47. Woodcock J, Givoni M, Morgan AS. Health impact modelling of active travel visions for England and Wales using an Integrated Transport and Health Impact Modelling Tool (ITHIM). PLOS ONE 2013;8:e51462.

48. Brand C, Goodman A, Rutter $\mathrm{H}$, et al. Associations of individual, household and environmental characteristics with carbon dioxide emissions from motorised passenger travel. Appl Energy 2013;104:158-69.

49. Brand C, Boardman B. Taming of the few-the unequal distribution of greenhouse gas emissions from personal travel in the UK. Energy Policy 2008;36:224-38.

50. Preston I, White V, Thumim J, et al. Distribution of carbon emissions in the UK: implications for domestic energy policy. Joseph Rowntree Found... 2013. (March 2013).

51. Milner J, Green R, Dangour AD, et al. Health effects of adopting low greenhouse gas emission diets in the UK. BMJ Open 2015;5:e007364

52. Pucher J, Buehler R. Making cycling irresistible: lessons from the Netherlands, Denmark and Germany. Transp Rev 2008;28:495-528.

53. Schepers P, Twisk D, Fishman E, et al. The Dutch road to a high level of cycling safety. Saf Sci 2015;92:264-73.

54. Aldred R, Elliott B, Woodcock J, et al. Cycling provision separated from motor traffic: a systematic review exploring whether stated preferences vary by gender and age. Transp Rev 2016;37:29-55.

55. Teschke K, Harris MA, Reynolds CCO, et al. Route infrastructure and the risk of injuries to bicyclists: a case-crossover study. $\mathrm{Am}$ $J$ Public Health 2012;102:2336-43.

56. Panter J, Heinen E, Mackett R, et al. Impact of new transport infrastructure on walking, cycling, and physical activity. Am J Prev Med 2016;50:e45-53

57. Capacci S, Mazzocchi M. Five-a-day, a price to pay: an evaluation of the UK program impact accounting for market forces. $J$ Health Econ 2011;30:87-98.

58. Lara J, Evans EH, O'Brien N, et al. Association of behaviour change techniques with effectiveness of dietary interventions among adults of retirement age: a systematic review and meta-analysis of randomised controlled trials. BMC Med 2014;12:177. 